\title{
SIBERIAN LIDAR STATION: INSTRUMENTS AND RESULTS
}

Gennadii G. Matvienko ${ }^{1,2}$, Yurii S. Balin ${ }^{1}$, Sergey M. Bobrovnikov ${ }^{1}$, Oleg A. Romanovskii ${ }^{1,2}$, Grigirii P. Kokhanenko ${ }^{1}$, Svetlana V. Samoilova ${ }^{1}$, Ioganes E. Penner ${ }^{1}$, Evgenii V. Gorlov ${ }^{1}$, Victir I. Zharkov $^{1}$, Sergey A. Sadovnikov ${ }^{1}$, Semen V. Yakovlev ${ }^{1,2}$, Oleg E. Bazhenov ${ }^{1}$, Sergey I. Dolgii ${ }^{1}$, Andrey P. Makeev ${ }^{1}$, Alexey A. Nevzorov ${ }^{1}$, Alexey V. Nevzorov ${ }^{1}$, Olga V. Kharchenko ${ }^{1}$

${ }^{1}$ V.E. Zuev Institute of Atmospheric Optics, Tomsk, Russia, *roa@iao.ru

${ }^{2}$ National Research Tomsk State University, Tomsk, Russia

\begin{abstract}
The Siberian Lidar Station created at V.E. Zuev Institute of Atmospheric Optics and operating in Tomsk $\left(56.5^{\circ} \mathrm{N}, 85.0^{\circ} \mathrm{E}\right)$ is a unique atmospheric observatory. It combines up-to-date instruments for remote laser and passive sounding for the study of aerosol and cloud fields, air temperature and humidity, and ozone and gaseous components of the ozone cycles. In addition to controlling a wide range of atmospheric parameters, the observatory allows simultaneous monitoring of the atmosphere throughout the valuable altitude range $0-75 \mathrm{~km}$. In this paper, the instruments and results received at the Station are described.
\end{abstract}

\section{INTRODUCTION}

Long-term routine measurements by lidar facilities are very effective. The analysis of the measurement data allows the development of empirical models of atmospheric parameters; determination of their seasonal, quasi-two-year, and other periodic cycles of variations; the study of causes that determine the dynamics and correlations between the parameters measured; detection of short-term atmospheric disturbances of slow variations under the action of natural and anthropogenic factors, and, finally, detection and forecast of trends in atmospheric variations with estimation of their effects on possible climate changes. The Siberian Lidar Station (SLS) is a unique atmospheric observatory created at V.E. Zuev Institute of Atmospheric Optics. It operates in Tomsk $\left(56.5^{\circ} \mathrm{N}, 85.0^{\circ}\right.$ E) and combines up-to-date instruments for remote laser and passive sounding of aerosol and cloud fields, air temperature and humidity, and ozone and gaseous components of the ozone cycles. In addition to controlling a wide range of atmospheric parameters, the observatory allows simultaneous monitoring of the atmosphere throughout the valuable altitude range $0-75 \mathrm{~km}$.
The possibility of simultaneous complex measurements of key climate forcing and ecological parameters of the atmosphere is a feature of measurements at SLS. It is provided by use of different laser sounding techniques in combination with spectrophotometric measurements This paper describes the monitoring of such atmospheric parameters as aerosols, temperature, clouds, ozone, gaseous components of ozone cycles at SLS.

\section{GENERAL SCEMATIC OF THE SLS MEASURING COMPLEX}

Experiments on the sounding of different atmospheric parameters (aerosols, temperature, ozone, humidity) have been carried out at the High-Altitude Sensing Station since 1991 using lidar channels with receiving mirrors of 2.2, 0.5 , and $0.3 \mathrm{~m}$ in diameters. The name "Siberian Lidar Station" was introduced in 1995, during preparation of documents for inclusion of the Station into the List of Unique Research and Experimental Systems of National Significance of Russian Federation (RF). For a long time (from 1986), SLS was the only station of routine lidar monitoring of the stratosphere not only on a great territory of Siberia, but in the whole Russia. Only in 2005, measuring lidar facilities were elaborated and then started operating in the Asian Russia, in Vladivostok and Surgut, within the CIS-LiNet network [1].

The main SLS components are mounted in a specially equipped four-storey building with shaft and hatch (Figure 1). Laser sources are located at vibration-resistant benches around the shaft at the ground level. The key component of SLS is a receiving mirror with a diameter of $2.2 \mathrm{~m}$ and a focal length of $10 \mathrm{~m}$; it is located on the same level inside the shaft on a vibro-isolated foundation. The focal plane of this mirror is formed at the level of the 3rd floor. The 
multichannel operation mode of the lidar with the receiving mirror of $2.2 \mathrm{~m}$ in diameter is possible due to the slight inclination of some sounding laser beams relative to the vertical. Thus, there is the possibility of simultaneous reception of up to nine optical signals. Additional receiving mirrors with smaller apertures and diameters of 0.3 and $0.5 \mathrm{~m}$ are mounted on the $3 \mathrm{rd}$ floor. They provide for the optimal lidar signal detection mode in different sounding altitude ranges due to different base distances between the axes of the receiving and transmitting antennas of the lidar channels. Lidar signals are detected in the photocurrent pulse counting mode. The sounding is carried out in the darkness hours.

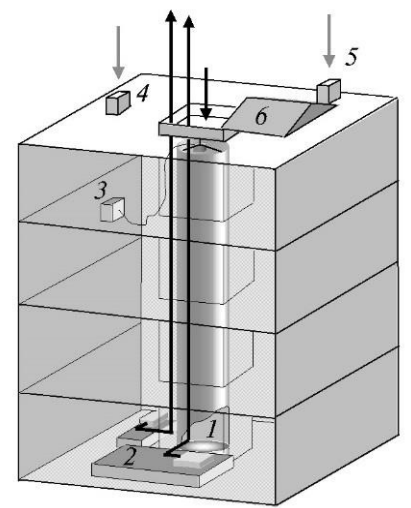

Figure 1 SLS building with the master receiving telescope in the shaft: $2.2 \mathrm{~m}$ mirror (1); laser benches

(2); receiving and recording equipment (3); M-124 ozonometer (4); twilight spectrophotometer (5); hatch

\section{SLS cover (6) \\ MULTICHANNEL LIDAR COMPLEX}

The stationary multichannel lidar complex of SLS has been developed with the use of laser sources of different types generating in the 266-1064 nm spectral region and receiving telescopes with 2.2, 0.5 , and $0.3 \mathrm{~m}$ diameter mirrors. Different sounding techniques allow the complex to receive information about the vertical distribution of some radiation significant atmospheric parameters, i.e., stratospheric ozone and aerosols, air temperature in the region from the tropopause to $\sim 80 \mathrm{~km}$, probably optical and geometrical parameters of high-level clouds, and humidity. The use of passive spectrophotometric sounding techniques allows measurements of the total ozone and total $\mathrm{NO}_{2}$ and their vertical distribution. Table 1 includes the main specifications of the laser sources and receiving optics of the complex.
Table 1 -Specifications of the SLS lidar complex

\begin{tabular}{|c|c|c|c|c|c|c|c|c|c|}
\hline Lidar & \multicolumn{9}{|c|}{ Measured parameter } \\
\hline parameter & \multicolumn{5}{|c|}{ Aerosols } & Tem & rature & \multicolumn{2}{|c|}{ Ozone } \\
\hline \multicolumn{10}{|c|}{ Transmitter } \\
\hline $\begin{array}{l}\text { Sounding } \\
\text { wavelength } \lambda \text {, } \\
\mathrm{nm}\end{array}$ & 511 & 532 & 355 & 683 & 1064 & & & $\begin{array}{l}308 \\
353\end{array}$ & $\begin{array}{l}299 \\
341\end{array}$ \\
\hline $\begin{array}{l}\text { Pulse energy, } \\
\mathrm{mJ} \text { (corr. } \lambda \text { ) }\end{array}$ & 1 & 100 & 40 & 60 & 200 & & & $\begin{array}{c}100 \\
50\end{array}$ & 20 \\
\hline $\begin{array}{l}\text { Pulse } \\
\text { frequency, } \\
\mathrm{Hz}\end{array}$ & 2500 & 15 & 15 & 15 & 15 & & & $\begin{array}{l}50- \\
200\end{array}$ & 15 \\
\hline $\begin{array}{l}\text { Divergence, } \\
\text { mrad }\end{array}$ & \multicolumn{5}{|c|}{$\sim 01$} & \multicolumn{2}{|c|}{0.1} & $\begin{array}{l}0.1- \\
0.3\end{array}$ & $\begin{array}{c}0.1- \\
0.3\end{array}$ \\
\hline \multicolumn{10}{|c|}{ Receiver } \\
\hline $\begin{array}{l}\text { Sounding } \\
\text { technique }\end{array}$ & \multicolumn{6}{|c|}{ Elastic backscattering } & $\begin{array}{l}\text { RS } \\
\text { by } \\
N_{2}\end{array}$ & \multicolumn{2}{|c|}{ DIAL } \\
\hline $\begin{array}{l}\text { Wavelength, } \\
\mathrm{nm}\end{array}$ & 511 & 532 & 355 & 683 & 1064 & 532 & 607 & $\begin{array}{l}308 \\
353\end{array}$ & $\begin{array}{l}299 \\
341\end{array}$ \\
\hline $\begin{array}{l}\text { Mirror } \\
\text { diameter, } \mathrm{m}\end{array}$ & 2.2 & 0.3 & 0.3 & 0.3 & 2.2 & 2.2 & $\begin{array}{l}2.2 \\
0.3\end{array}$ & 0.5 & 0.5 \\
\hline $\begin{array}{l}\text { Focal length, } \\
\mathrm{m}\end{array}$ & 10 & 1 & 1 & 1 & 10 & 10 & $\begin{array}{c}10 \\
1\end{array}$ & 1.5 & 1.5 \\
\hline \multicolumn{10}{|c|}{ Interference filters } \\
\hline $\begin{array}{l}\text { Maximal } \\
\text { transmittance, } \\
\% \%\end{array}$ & 65 & 62 & 60 & 68 & 60 & 62 & 70 & $\begin{array}{l}56 \\
60\end{array}$ & $\begin{array}{l}42 \\
50\end{array}$ \\
\hline $\begin{array}{l}\text { Bandwidth at } \\
\text { the level } \\
0.5 T, n m\end{array}$ & 1.8 & 2 & 5 & 2 & 3.9 & 2 & 1.8 & $\begin{array}{c}4.5 \\
6\end{array}$ & $\begin{array}{c}3.6 \\
4\end{array}$ \\
\hline
\end{tabular}

Today, the SLS lidar measurement complex includes two independent lidar systems (Figure 2): a system for measuring parameters of the stratospheric aerosol layer and the middle atmosphere temperature (a) and a lidar for sounding the vertical distribution of the ozone concentration over the stratosphere (b). Figure $3 \mathrm{a}$ shows that the system developed provides for lidar signal recording from up to the upper boundary of the stratospheric aerosol layer, $\sim 30$ $\mathrm{km}$. Figure $3 \mathrm{~b}$ shows the profiles of the scattering ratio $\mathrm{R}(\mathrm{H})$, which exemplify the three-frequency stratospheric aerosol sounding results under the presence of traces of volcanogenic aerosols emitted during the explosions of Okmok and Kasatochi volcanoes.

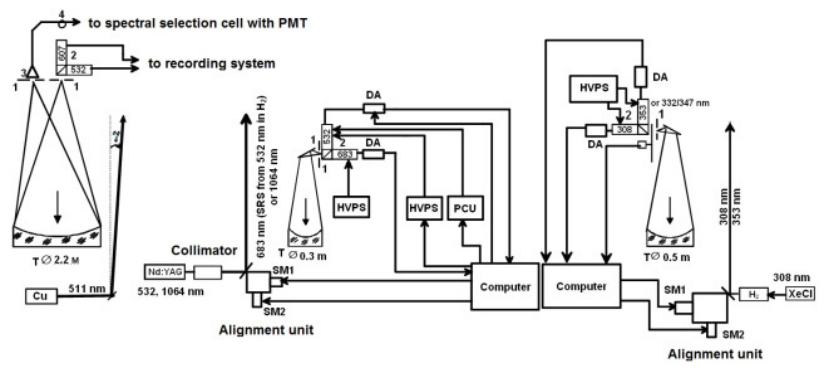

Figure 2 - Schematic of SLS multichannel measuring complex: field stops (1); spectral selection cell with PEM (2); focon (3); light guide (4); mechanical obturator (5); solid laser (Nd:YAG); eximer laser (XeCl); $\mathrm{Cu}$ vapor laser (Cu); SRS conversion cell filled with hydrogen $\left(\mathrm{H}_{2}\right)$; collimator $(\mathrm{C})$; discriminator amplifier (DA); high-voltage power supplies (HVPS); step motors (SM) 

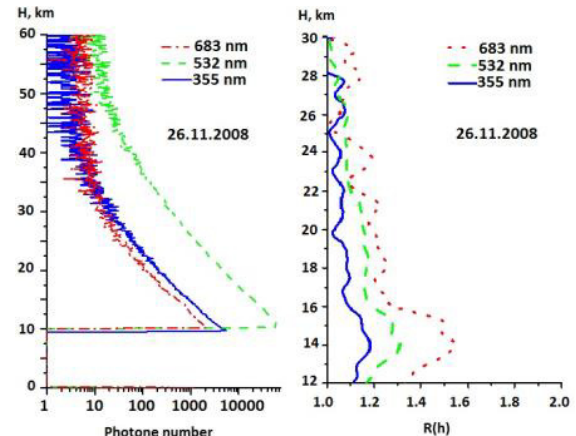

Figure 3 - Lidar signals at three sounding wavelengths

(a) and altitude profiles of the scattering ratio retrieved for November 11, 2008 (b)

\section{MULTIWAVELENGTH POLARIZATION LIDAR LOZA-S}

The stationary LOZA-S lidar has been designed and created at the Institute of Atmospheric Optics. It ensures simultaneous recording of lidar signals of elastic and Raman scattering (RS) when irradiating a medium at wavelengths of 1064, 532, and $355 \mathrm{~nm}$. The lidar (Figure 4) is based on a LOTIS-2135 Nd:YAG laser and a receiving Cassegrain mirror telescope with a diameter of $300 \mathrm{~mm}$. Lidar specifications are given in Table 2.

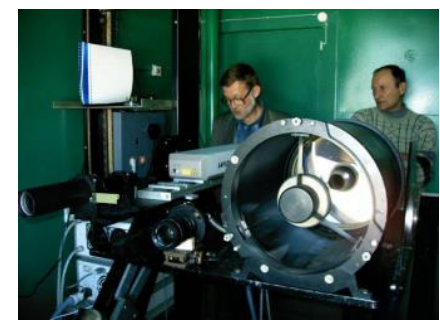

Figure 4 - LOZA-S lidar

Table 2 - Stationary lidar LOSA-S

Coordinates: $56.48 \mathrm{~N}, 85.05 \mathrm{E}$;

Altitude range, approx. $0.1-20 \mathrm{~km}$

Spatial resolution $1.5-12 \mathrm{~m}$

Radiation wavelength:

Pulse energy (typ.):

Pulse frequency (typ.):

Beam divergence:

Telescope:

Objective diameter:

Focus length:

$355,532,1064 \mathrm{~nm}$

$160,400,700 \mathrm{~mJ}$

$10 \mathrm{~Hz}$

$0.2 \mathrm{mrad}$

Cassegrain

$300 \mathrm{~mm}$

$1500 \mathrm{~mm}$

The LOZA-S lidar was used for routine measurements of the vertical aerosol distribution in Tomsk. On the basis of these measurements, the altitude distribution of tropospheric aerosol layers was analyzed, including the boundary layer, which consists of internal mixing layer, mixing layer, and entrainment layer, and the middle tropospheric layer. Figure 4 exemplifies lidar signals detected in day- and nighttime; RS signals were recorded in the photon counting mode in darkness hours.

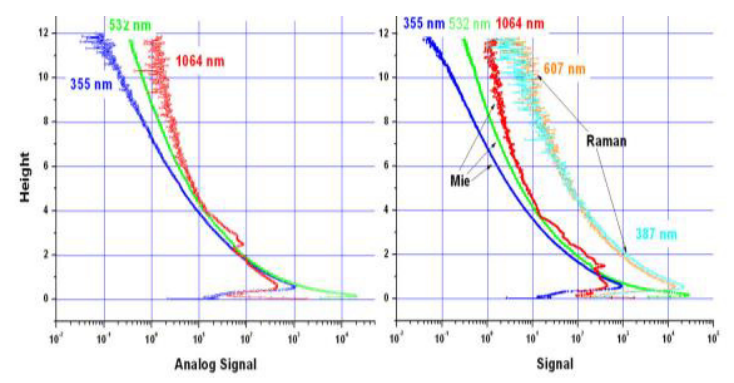

Figure 4-LOZA-S lidar signals when sounding in day (left) and nighttime (right)

\section{REMOTE MEASUREMENTS OF THE TEMPERATURE IN THE STRATOSPHERE AND MESOSPHERE}

Figure 5 shows the optical schematic of the temperature channel of the complex mean pure rotational Raman scattering (PRRS) lidar of SLS. It was used for testing the technique for discrimination of the regions of pure rotational SR spectrum with the help of a double monochromator. A Powerlight 9030B Nd:YAG laser is used as a source of exciting radiation.

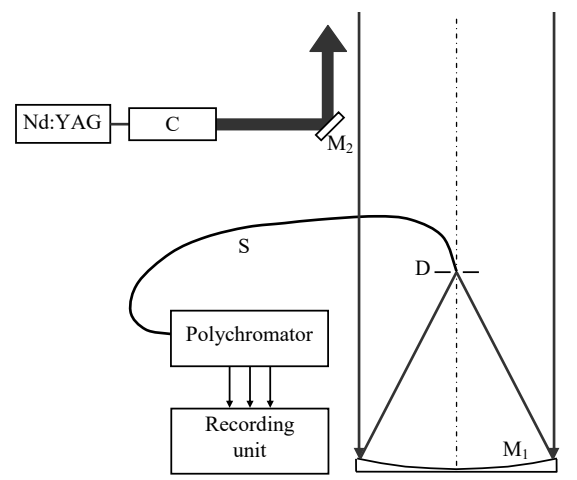

Figure 5 Schematic structure of the temperature channel of the PRRS lidar: main mirror of the receiving telescope of $2.2 \mathrm{~m}$ in diameter $\left(M_{I}\right)$, receiver's deflecting mirror $\left(M_{2}\right)$, field stop $(D)$, light guide (S), collimator (C)

Figure 6 shows the lidar response of the pure rotational RS spectrum in the presence of a deep ice crystal cloud. A high level of suppression of the unbiased scattering provides for a high quality of the Raman signal at the lower boundary and inside the cloud. 


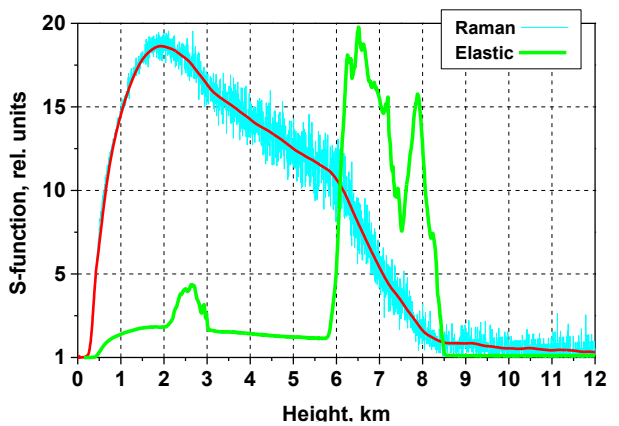

Figure 6 Lidar response of the pure rotational $R S$ spectrum in the presence of a deep ice crystal cloud

\section{LIDAR FOR OZONE SENSING}

The sounding wavelengths selected 299/341 nm were used in the ozone lidar designed. The 4th harmonic $266 \mathrm{~nm}$ of the fundamental frequency of a Nd:YAG laser (LS-2134UT laser, LOTIS TII company, Minsk) is used as a laser radiation source, which is then converted in hydrogen in the 1st $(299 \mathrm{~nm})$ and 2nd $(341 \mathrm{~nm})$ Stokes components. Ozone profiles retrieved from lidar sounding data are compared with the IASI/MetOp satellite measured profiles. The range of lidar signal detection was from 5 to $18 \mathrm{~km}$. The lidar measurements show the ozone behavior in more detail. Figure 7 shows all the considered cases of comparison of ozone profiles measured at the SLS and retrieved from IASI data. The measurements are reduced to the total altitude range $6-15 \mathrm{~km}$ for convenience. Increased ozone concentrations measured at the SLS as compared to IASI are seen in the range from 8.5 to $12.5 \mathrm{~km}$ throughout the whole observation period.

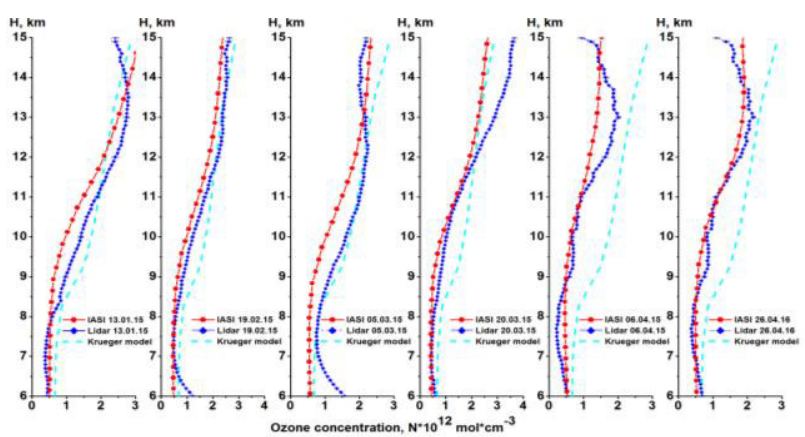

Figure 7 Comparison of vertical profiles of ozone

\section{OPO LIDAR SYSTEM}

SLS includes an OPO lidar for remote gas analysis of the atmosphere in the 3-4 $\mu \mathrm{m}$ spectral range. A pumping wavelength of $1064 \mathrm{~nm}$ is transformed by means of OPO based on nonlinear KTP and KTA crystals. Crystal turn allows turning the radiation wavelength in the 3-4 $\mu \mathrm{m}$ spectral range. The main OPO lidar specifications are given in Table 3.

Table 3 Specification of the experimental setup

\begin{tabular}{|l|l|}
\hline Laser maximal pulse energy, mJ & 9 \\
\hline Laser pulse length, $\mathrm{ns}$ & $10-13$ \\
\hline Laser pulse frequency, $\mathrm{Hz}$ & 10 \\
\hline Laser beam divergence, $\mathrm{mrad}$ & 2 \\
\hline Main mirror diameter, $\mathrm{mm}$ & 300 \\
\hline Focal length, mm & 120 \\
\hline Photodetector spectral range, $\mu \mathrm{m}$ & $1-4$ \\
\hline Diameter of photodiode detection area, $\mu \mathrm{m}$ & 300 \\
\hline Input rise time, ns & 50 \\
\hline
\end{tabular}

Energy parameters of a laser system have been measured in experiments. The sounding path is 20 $\mathrm{m}$ long. Backscattered radiation is gathered by a receiving telescope and focused to the PD38-03PR (IBSG Co., St-Peterburg, Russia) photodiode detection area. The level of signals with the use of the above optical elements allows a suggestion about possibilities of sounding the atmosphere along a surface tropospheric path up to $1 \mathrm{~km}$ long. Figure 8 shows lidar signals: minimum signals (black curve), maximum signals (blue curve), result of averaging of lidar signals (red curve) in the $3-4 \mu \mathrm{m}$ spectral region.

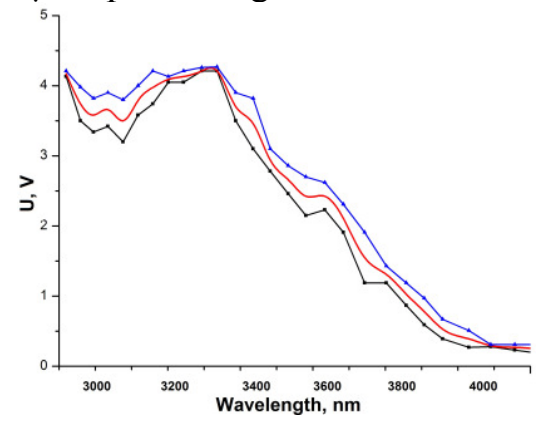

Figure 8 OPO lidar signals

\section{ACKNOWLEDGEMENTS}

The work was supported by the Russian Science Foundation (Agreement 15-17-10001 in part of the ozone lidar measurements) and President of the Russian Federation (grant MK-1367.2017.5 in the part of the experiments on recording lidar signals of the broadband mid-IR lidar).

\section{References}

[1] Chaykovskii A.P., Ivanov A.P., Balin Yu.S., El'nikov A.V., Tulinov G.F., Plusnin I.I., Bukin O.A., Chen B.B., 2005: CIS-LiNet lidar network for monitoring aerosol and ozone: methodology and instrumentation, Atmospheric and oceanic optics, 18 (12), 958-964. 